\title{
Hf-Nd isotope decoupling in the mantle: a brief review and new geodynamic perspectives
}

\author{
R. TILHAC ${ }^{1,2^{*}}$, G.C. BEGG ${ }^{2,3}$, S.Y. O'REILLY ${ }^{2}$, \\ W.L.GRIFFIN ${ }^{2}$ \\ ${ }^{1}$ Faculty of Geosciences and Civil Engineering, Institute of \\ Science and Engineering, Kanazawa University, Japan \\ ${ }^{2}$ ARC Centre of Excellence for Core to Crust Fluid Systems \\ (CCFS) and GEMOC, Department of Earth and \\ Environmental Sciences, Macquarie University, Australia \\ ("correspondence: romain.tilhac@mq.edu.au) \\ ${ }^{3}$ Minerals Targeting International, Perth, Australia
}

Since the early 1980's, the combined application of the $\mathrm{Lu}-\mathrm{Hf}$ and $\mathrm{Sm}-\mathrm{Nd}$ isotope systems to oceanic lavas has significantly contributed to understanding the Earth's crustmantle system, from magma genesis to sediment recycling. With the democratization of MC-ICP-MS, Hf-isotope studies of peridotites have increasingly reported the preservation of highly depleted, possibly ancient residues, in agreement with Re-Os data, and the decoupling of $\mathrm{Hf}$ and $\mathrm{Nd}$ isotopes.

To provide a comprehensive view on this topic, we have compiled all Hf-Nd isotope data published to date on abyssal, orogenic and ophiolitic peridotites and pyroxenites, and basalt- and kimberlite-borne mantle xenoliths. We review the mechanisms accounting for their isotopic signature. Decoupled compositions are common $(\sim 40 \%$ of data have $\left.\Delta \varepsilon_{\mathrm{Hf}}>10\right)$, with little regard of the tectonic settings, and particularly associated with LREE enrichment, reflecting the dominant role of melt-peridotite interaction. Nd-isotope compositions are often completely reset, resulting in a wide range of $\varepsilon_{\mathrm{Hf}}$ at nearly constant $\varepsilon_{\mathrm{N}}$. The geochronological significance of this large variability for radiogenic Hf is not straightforward as it may result from variously depleted and/or ancient protoliths, and from the partial resetting of $\mathrm{Hf}$.

The dataset is used along with the Global Lithospheric Architecture Mapping (GLAM) systematics [1] to envisage further geodynamic perspectives. We use a discrimination based on the tectonothermal age (i.e. Tecton, Proton, Archon, etc.) to suggest that the ubiquity of highly radiogenic $\mathrm{Hf}$ compositions decoupled from $\mathrm{Nd}$ may reflect the preservation of ancient (Archean) mantle, variously reworked by arc magmatism during successive subduction-collision episodes. It may also provide an alternative to explain the slight shift observed (if any) between the Hf-Nd mantle array and Bulk Silicate Earth, commonly ascribed to a "missing component". The extent to which such depleted domains can contribute (potentially as melts) to basalt genesis is also discussed.

[1] Begg et al., 2009, Geosphere 5, 23-50. 